\title{
Arqueofauna do Sítio Piracanjuba, Piraju-SP
}

\author{
Manoel Mateus Bueno Gonzalez* \\ Silvia Cristina Piedade** \\ José Luiz de Morais**
}

GONZALEZ, M.M.B.; PIEDADE, S.C.; MORAIS, J.L. Arqueofauna do Sítio

Piracanjuba, Piraju-SP. Revista do Museu de Arqueologia e Etnologia, São Paulo, 17: 231-249, 2007

Resumo: O objetivo deste trabalho foi analisar a subsistência dos Guaranis da região de Piraju-SP, pelo estudo dos vestígios faunísticos do Sítio Piracanjuba. Constatou-se a predileção de animais de médio a grande porte na subsistência desses grupos, além da ausência expressiva de peixes que pode estar ligada a tabus ou devido aos processos tafonômicos.

Palavras-Chave: Zooarqueologia - Arqueofauna - Guarani.

\section{Introdução}

análise do EIA/RIMA da Usina

Hidrelétrica de Piraju permitiu

observar a grande variedade de plantas e animais comestiveis que ocorrem na área e que certamente deve ter sido fonte de recursos alimentares para os índios desta região, tendo em vista as condições, circunstâncias e influências que afetaram o desenvolvimento cultural desses grupos (Bower 1986; Belovsky 1987; Davis 1987) .

O objetivo deste trabalho foi estabelecer de forma sistemática a subsistência específica dos Guaranis da região de Piraju-SP, pela análise zooarqueológica dos vestígios faunísticos

(*) Centro Regional de Pesquisas Arqueológicas do NUPEC. Santos, SP.gonzalez@nupec.com.br

$\left.{ }^{* *}\right)$ Museu de Arqueologia e Etnologia da Universidade de São Paulo.S.C.P (silviapied@uol.com.br);

J.L.M. (jlmorais@uol.com.br) coletados durante as escavações, utilizando-se metodologia controlada de intervenção.

\section{Local de estudo}

O Sitio Piracanjuba está localizado à jusante do Rio Paranapanema no Município de Piraju, estado de São Paulo (Fig.1), coordenadas: $E=0.666 .760 \mathrm{~m} ; \mathrm{N}=7.438 .560 \mathrm{~m} \mathrm{e}$ $\mathrm{A}=568,20 \mathrm{~m}$. O referido sítio faz parte do projeto de Salvamento Arqueológico da Usina Hidrelétrica Piraju - ArqPiraju, em decorrência de contrato firmado entre o Museu de Arqueologia e Etnologia da USP e a Companhia Brasileira de Alumínio, sob a coordenação geral de José Luiz de Morais.

Durante os trabalhos foram identificadas quatro manchas de solo antropogênico (NSA) na área do sítio (Fig. 2), remanescentes de antiga aldeia de populações agricultoras pertencentes ao Sistema Regional Guarani (Morais 1999). Estes grupos ocuparam o sítio 


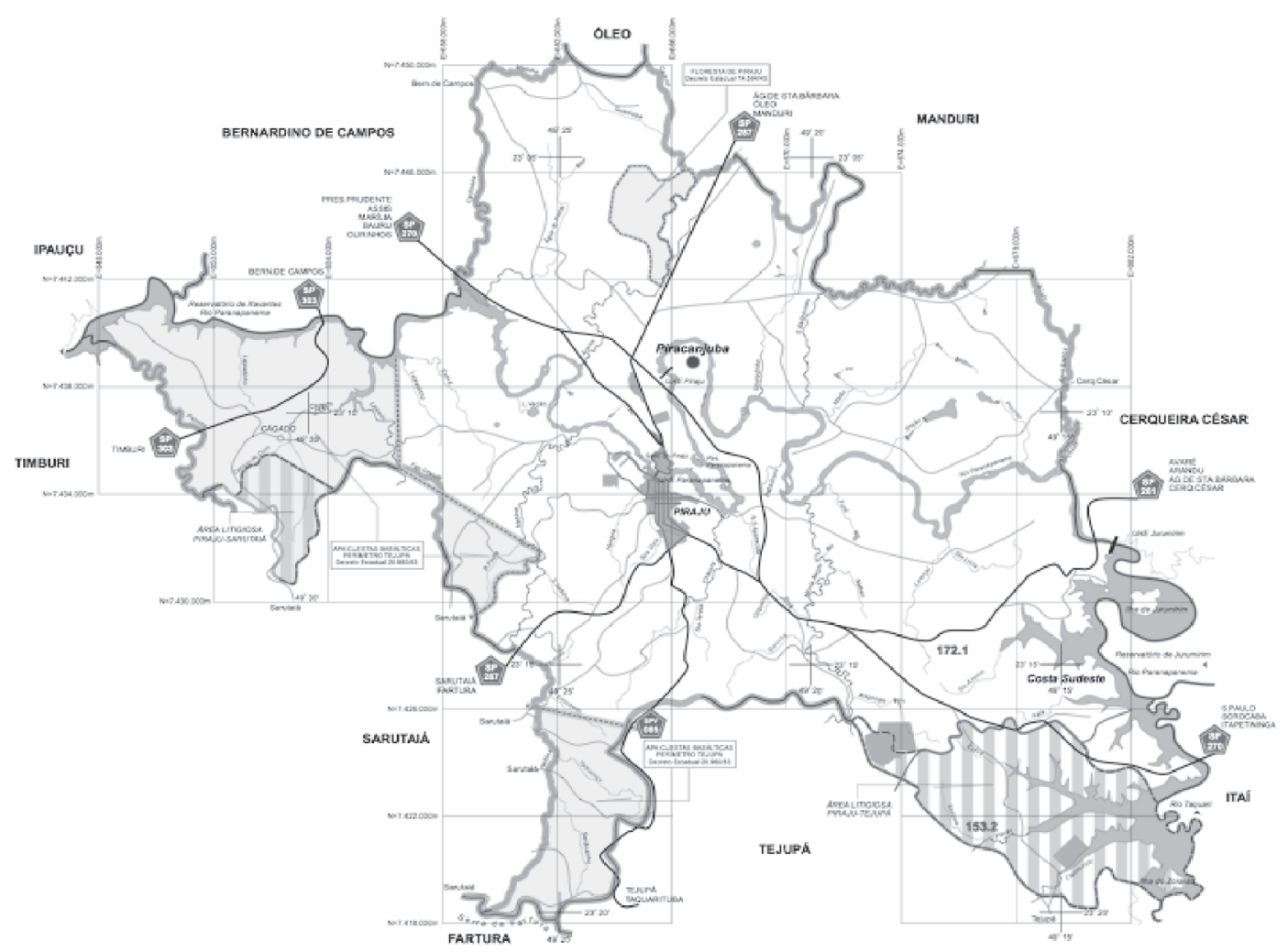

Fig. 1. Localização do Sitio Piracanjuba, Município de Piraju, estado de São Paulo.

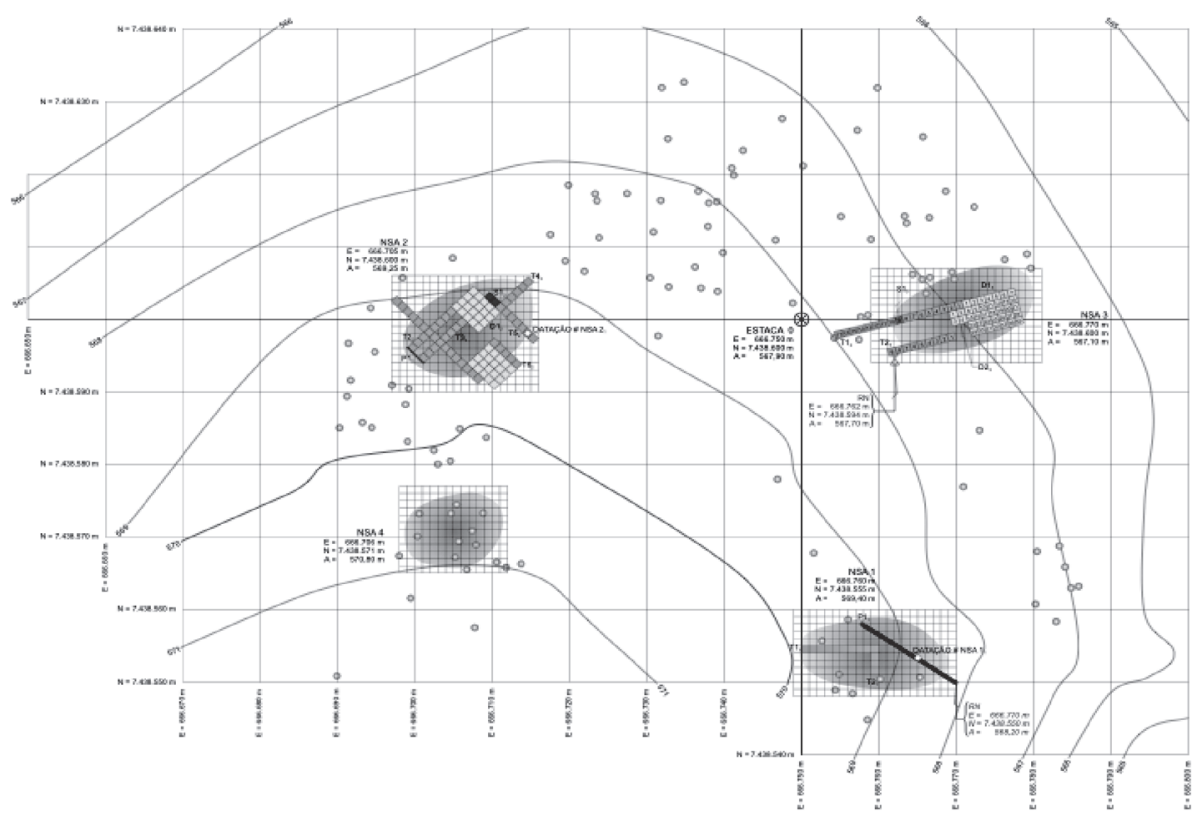

Fig. 2. Croquis esquemático dos Núcleos de Solo Antropogênico (NSA, NSA1, NSA2 e NSA3). 
por volta dos séculos XIV ao XVII, segundo datações obtidas por termoluminescência e Carbono 14, além da análise dos artefatos cerâmicos coletados em etapas anteriores.

Para a coleta e análise da arqueofauna foi escolhida o NSA1 justificada pela presença de grande quantidade de ossos visíveis na superfície da mancha e por não ter sofrido nenhum tipo de intervenção em etapas anteriores de pesquisa de campo.

\section{Procedimentos de campo}

Foram abertas duas trincheiras na mancha de sedimento escuro do solo antropogênico (NSA 1) (Fig. 3), a Trincheira 1 (T1) com dez quadrículas e a Trincheira 2 (T2) com três quadrículas, de forma que parte da T1 ficasse na terra preta e parte fora da mancha. A T2, localizada fora da mancha, foi aberta apenas para coleta de sedimento para análise. As trincheiras foram divididas em quadrículas de $1 \times 1 \mathrm{~m}$, ficando a $\mathrm{T} 1 \mathrm{com} 10 \mathrm{~m}$ de comprimento e a $\mathrm{T} 2$ com $3 \mathrm{~m}$.

Os trabalhos foram iniciados pela decapagem manual das quadrículas obedecendo os estratos artificiais de 10 em $10 \mathrm{~cm}$, a partir do nível "0" arbitrário, tomado do ponto mais alto da Q\#1 até atingir aproximadamente de $-40 \mathrm{a}-50 \mathrm{~cm}$ de profundidade.

Foram coletadas amostras de sedimentos para triagem de material pela técnica de flotação e para análise química do solo na porção central de cada quadrícula, no estrato aproximado de -10 a $-20 \mathrm{~cm}$ de profundidade.

Os fragmentos cerâmicos e líticos foram processados e analisados no Centro Regional de Piraju e o material faunístico e artefatos ósseos no NUPEC/CERPA, em Santos.

Para contextualizar a fauna encontrada, os estratos artificiais de $10 \mathrm{em} 10 \mathrm{~cm}$ foram denominados como segue: $0 \mathrm{a}-10 \mathrm{~cm}=$ estrato I; -10 a $-20 \mathrm{~cm}=$ estrato II ; -20 a $30 \mathrm{~cm}=$ estrato III $;-30$ a $-40 \mathrm{~cm}=$ estrato $\mathrm{IV} ;-40$ a $-50 \mathrm{~cm}=$ estrato $\mathrm{V}$.

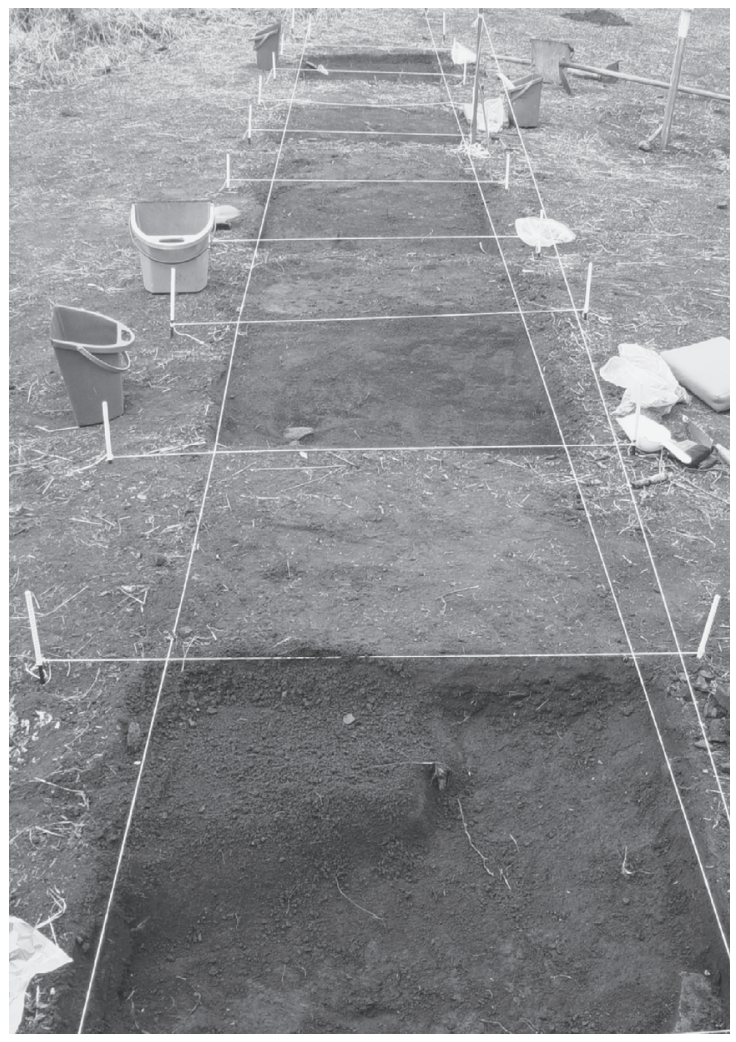

Fig. 3. Abertura da T1. Escavação inicial das Q\#1,3,5,7 e 9. As quadrícula \#1 e 3 estão localizadas na mancha de terra preta. Direção EW. Foto: Everson P. Fogolari.

\section{Procedimentos de laboratório}

Os vestígios faunísticos coletados passaram pelo processo de lavagem e secagem, obedecendo à separação específica das quadras e estratos. A lavagem foi realizada sob água corrente com o auxílio de uma pequena escova para auxiliar na retirada do sedimento para possibilitar uma perfeita identificação. $\mathrm{O}$ processo de secagem foi realizado à temperatura ambiente devido às condições tafonômicas dos vestígios faunísticos.

Em seguida, os elementos foram separados, identificados e catalogados por grupos taxonômicos específicos, de acordo com as possibilidades, devido ao elevado grau de fragmentação causado por processos tafonômicos e antrópicos. A identificação taxonômica foi realizada com o auxílio das coleções osteológicas do Centro Regional de 
Pesquisas Arqueológicas do Núcleo de Pesquisa e Estudo em Chondrichthyes - NUPEC/CERPA, do Museu de Arqueologia e Etnologia da USP MAE-USP e pelo levantamento de publicações específicas dos gêneros.

Nas amostras de solo do estrato arqueológico $(1000 \mathrm{~g})$ referente às quadras $1(-10 \mathrm{a}-$ $20 \mathrm{~cm})$ e $2(-10 \mathrm{a}-20 \mathrm{~cm})$, foi realizado o exame de flotação, a qual geralmente é empregada para a recuperação de elementos faunísticos (pequenas vértebras e escamas) e botânicos (sementes), que muitas vezes não são detectadas durante o processo de escavação e no ato de peneirar o sedimento escavado.

\section{Resultados}

Durante a decapagem foram identificadas três camadas de sedimentos: a primeira, de sedimento marrom escuro (5 YR 2.5/1- black), que chamaremos neste trabalho de (1), ocorreu nos primeiros estratos e apresentou uma espessura de $\sim 30 \mathrm{~cm}$. É composto principalmente de carvão, fragmentos cerâmicos em abundância, líticos lascados, vestígios faunísticos (queimados ou não), como ossos de mamíferos, peixes, répteis, aves, além de dentes de animais (porco do mato, macaco) e conchas de moluscos, gastrópodes e bivalves, terrestres e fluviais, marinhos e dulcícolas. Presença de muitos coquinhos queimados e sementes de mamona. Todo esse material apresentava-se extremamente friável, muitas vezes se desmanchando ao menor toque.

O segundo sedimento, marrom avermelhado escuro (2), (5 YR 3/3 dark reddish brown), é de transição entre o solo orgânico e o latossolo. Apresenta fragmentos cerâmicos, porém, em menor quantidade que no sedimento (1), além de carvão esparso e raros fragmentos ósseos. $\mathrm{Na}$ camada de latossolo, marrom avermelhado claro (3) (5 YR 4/6 yellowish red), ocorreram raríssimos restos faunísticos e poucos fragmentos cerâmicos. (Fig.4)

\section{Fauna de superfície e estratos}

Ao analisar o material do estrato I $(0$ a -10 $\mathrm{cm})$, verificou-se que as concentrações de elementos faunísticos são mais regulares (Anexo

Sítio Piracanjuba - Piraju - SP

NSA 1 - Trincheira 1

Perfil Parede Sul - 13/05/04

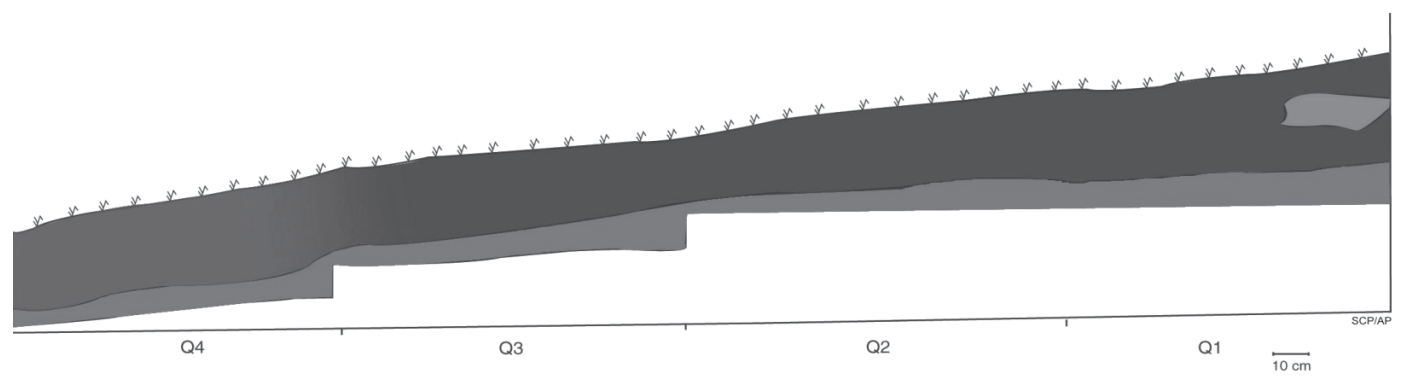

Sedimento marrom escuro (solo antropogênico) rico em carvão, restos faunísticos e cerâmica, além de grande quantidade de coquinho queimado.

Sedimento marrom avermelhado escuro, com pouco carvão, cerâmica e ausência de fauna.

Fig. 4. Croquis esquemático do perfil estratigráfico da trincheira 1. 
I). Os gastrópodes e bivalves (Tabela I) que possuem como principais representantes os gêneros Diplodon e Aylacostoma (Fig. 5) são mais evidentes dentro do pacote arqueológico. Os mamíferos estão bem representados pelos gêneros Mazama (veado) (Fig. 6), Hydrochaeris (capivara) e Agouti (paca) (Tabela II). Os demais mamíferos são menos freqüentes como os dos gêneros Tayassu pecari (porco-do-mato) e Puma concolor (suçuarana) (Tabela III).

Os peixes e aves que apresentaram baixa freqüência ou estavam ausentes em outras etapas de escavação, aparecem com melhor representatividade neste trabalho de campo, ressaltando para os peixes a presença do gênero Potamotrygon (raia de água doce) e para as aves o gênero Tinamus (macuco).

A freqüência de aparecimento da fauna é constante até o final do estrato II (Anexo II). Nos estratos III (Anexo III) e IV (Anexo IV) não ocorrem muitas alterações no aspecto qualitativo, mas mostram-se bem acentuados no aspecto quantitativo. A quantidade de ossos de mamíferos indeterminados é muito grande devido ao seu elevado grau de fragmentação.
Os elementos faunísticos de répteis são escassos, ocorrendo algumas vértebras de serpentes pertencentes às famílias Colubridae e Viperidae, assim como fragmentos de ossos craniais de cágados que são muito comuns na região. Não foram encontrados quaisquer tipos de fragmentos identificáveis para os anfíbios (rã, perereca e sapo).

\section{Análise da arqueofauna}

Tanto para os arqueólogos como para os tafonomistas é importante o conhecimento dos processos naturais que podem modificar o esqueleto, elementos do esqueleto e o tecido esquelético. Os processos tafonômicos são iniciados durante a vida do indivíduo (modificações antemortem) (Baker \& Brothwell 1980), mas muitos pesquisadores tomam como ponto de partida a hora da morte do animal (modificações perimortem) (Noe-Nygaard 1975) e seguem com todas as demais alterações denominadas postmortem (White 1992).

Tabela I

\begin{tabular}{ccc}
\hline & Malacofauna do Sítio Piracanjuba* & \\
\hline TAXA & NOME COMUM & SETOR \\
\hline $\begin{array}{c}\text { CLASSE BIVALVIA } \\
\text { Família Hyriidae } \\
\text { Diplodon sp. }\end{array}$ & NSA1 \\
$\begin{array}{c}\text { CLASSE GASTROPODA } \\
\text { Família Thiaridae } \\
\text { Aylacostoma tennuilabris }\end{array}$ & Desconhecido & \\
$\begin{array}{c}\text { Família Megalobulimidae } \\
\text { Megalobulimus sp. }\end{array}$ & NSA1 e NSA2 \\
$\begin{array}{l}\text { Família Neritidae } \\
\text { Neritinia virginea } \\
\text { Família Olividae } \\
\text { Olivancillaria cf. Urseus }\end{array}$ & Desconhecido & NSA1 \\
Família Orthalicidae & & NSA1 \\
Naesiotus sp. & Desconhecido & NSA1 \\
\hline
\end{tabular}

* Considerando a arqueofauna coletada em todas as etapas de campo. 


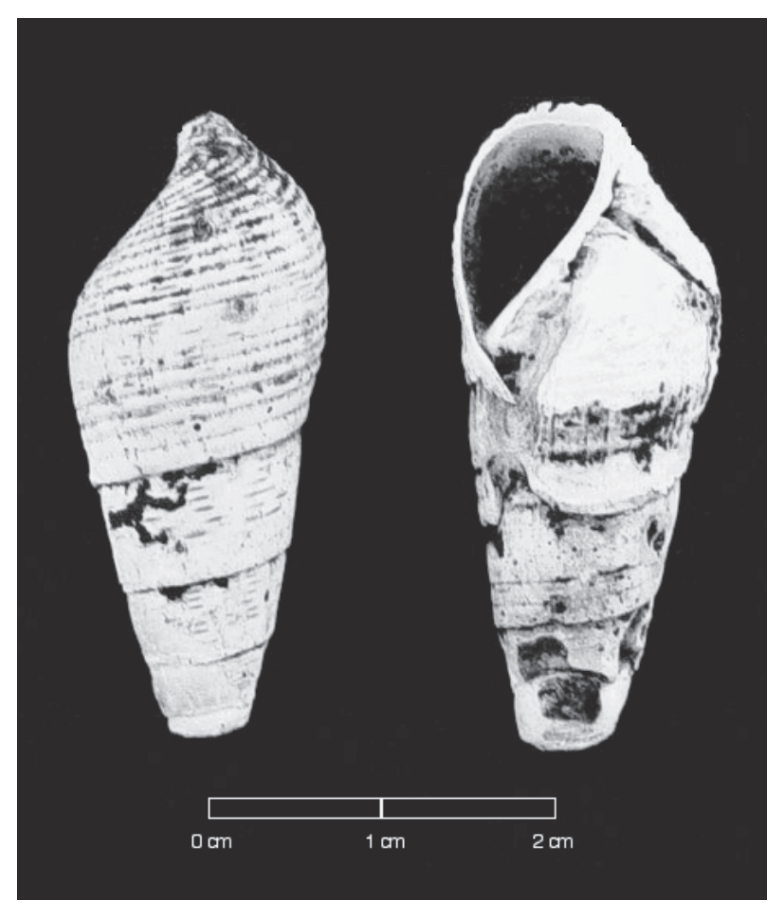

Fig. 5. Exemplares do gastrópode Aylacostoma tenuilabris.

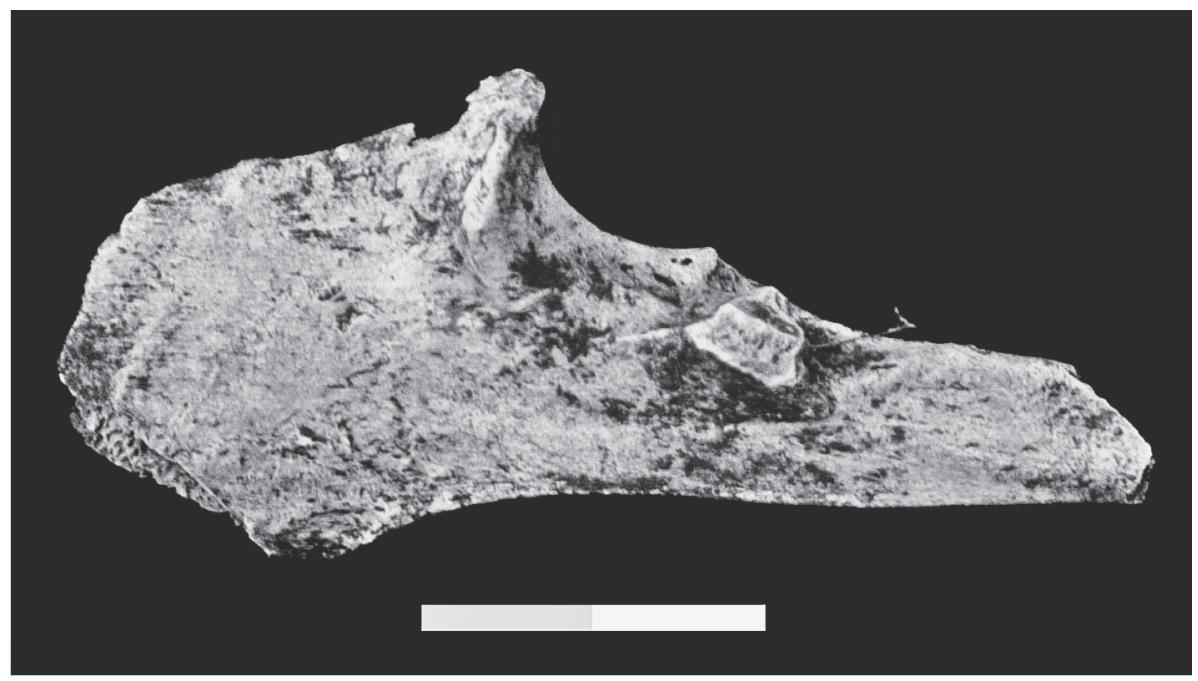

Fig. 6. Ulna de veado, Mazama sp. Escala $=1 \mathrm{~cm}$. 
Tabela II

\begin{tabular}{|c|c|c|c|}
\hline \multicolumn{4}{|c|}{ Arqueofauna de vertebrados do Sítio Piracanjuba* } \\
\hline TAXA & $\operatorname{PESO}(\mathrm{g})^{* *}$ & SETOR & NOME COMUM \\
\hline $\begin{array}{c}\text { CLASSE CHONDRICHTH } \\
\text { Ordem Rajidae } \\
\text { Família Potamotrygonidae } \\
\text { Potamotrygon sp. }\end{array}$ & 4500 & NSA 1 & Raia-de-água-doce \\
\hline $\begin{array}{c}\text { CLASSE ACTINOPTERYG } \\
\text { Ordem Characiformes } \\
\text { Família Characidae } \\
\text { Família Siluridae }\end{array}$ & & $\begin{array}{l}\text { NSA1, NSA2 } \\
\text { NSA } 1\end{array}$ & $\begin{array}{l}\text { Peixes } \\
\text { Peixes }\end{array}$ \\
\hline $\begin{array}{l}\text { CLASSE REPTILIA } \\
\text { Ordem Testudines } \\
\text { Família Chelidae }\end{array}$ & & NSA2 & Cágados \\
\hline CLASSE AVES & & NSA1, NSA2 & Aves \\
\hline $\begin{array}{l}\text { CLASSE MAMMALIA } \\
\text { Ordem Primates } \\
\text { Família Cebidae } \\
\text { Alouatta sp. } \\
\text { Cebus apella }\end{array}$ & $\begin{array}{l}6000 \\
2500\end{array}$ & $\begin{array}{c}\text { NSA1 } \\
\text { NSA,NSA1,NSA2 }\end{array}$ & $\begin{array}{c}\text { Bugio } \\
\text { Macaco-prego }\end{array}$ \\
\hline $\begin{array}{l}\text { Ordem Carnívora } \\
\text { Família Canidae } \\
\text { Speothos venaticus }\end{array}$ & 6000 & NSA1, NSA2 & Cachorro-do-mato \\
\hline $\begin{array}{l}\text { Família Felidae } \\
\text { Leopardus pardalis } \\
\text { Puma concolor }\end{array}$ & $\begin{array}{l}10000 \\
74500\end{array}$ & $\begin{array}{c}\text { NSA } \\
\text { NSA2 }\end{array}$ & $\begin{array}{l}\text { Jaguatirica } \\
\text { Suçuarana }\end{array}$ \\
\hline $\begin{array}{l}\text { Ordem Perissodactyla } \\
\text { Famíla Tapiridae } \\
\text { Tapirus terrestris }\end{array}$ & 23900 & NSA2, NSA3 & Anta, tapir \\
\hline $\begin{array}{l}\text { Ordem Artiodactyla } \\
\text { Família Tayassuidae } \\
\text { Tayassu pecari }\end{array}$ & 30000 & NSA1, NSA2 & Porco-do-mato \\
\hline $\begin{array}{l}\text { Família Cervidae } \\
\text { Mazama sp. }\end{array}$ & 20000 & NSA,NSA1,NSA2 & Veado \\
\hline $\begin{array}{l}\text { Ordem Rodentia } \\
\text { Família Hydrochaeridae } \\
\text { Hydrochaeris hydrochaeris }\end{array}$ & 50000 & NSA1 & Capivara \\
\hline $\begin{array}{c}\text { Família Agoutidae } \\
\text { Agouti paca }\end{array}$ & 8227 & NSA2 & Paca \\
\hline $\begin{array}{c}\text { Família Dasyproctidae } \\
\text { Dasyprocta sp. }\end{array}$ & 2500 & NSA1 & Cutia \\
\hline
\end{tabular}

*Considerando a arqueofauna coletada em todas as etapas de campo.

**Peso estimado das espécies viventes de acordo com Fonseca et al. (1996). 
Tabela III

\begin{tabular}{llrr}
\hline \multicolumn{2}{c}{ Ocorrência dos elementos faunísticos do Núcleo de Solo Antropogênico - NSA-1 } \\
\hline \multicolumn{1}{c}{ TAXA } & NOME COMUM & NISP & MINI \\
\hline \hline Aylacostoma tennuilabris & - & 16 & 16 \\
Diplodon sp. & - & 122 & 33 \\
Megalobulinus sp. & - & 16 & 2 \\
Potamotrygon sp. & Raia-de-água-doce & 1 & 1 \\
Tinamus sp. & Macuco & 2 & 1 \\
Agouti paca & Paca & 4 & 1 \\
Alouatta sp. & Bugiu & 5 & 1 \\
Cebus apela & Macaco-prego & 4 & 2 \\
Dasyprocta sp. & Cutia & 4 & 1 \\
Puma concolor & Suçuarana & 1 & 1 \\
Hydrochaeris hydrochaeris & Capivara & 3 & 1 \\
Mazama sp. & Veado & 6 & 2 \\
Spheotos sp. & Cachorro-do-mato & 2 & 1 \\
Tapirus terrestris & Anta & 2 & 1 \\
Tayassu pecari & Porco-do-mato & 2 & 1 \\
Peixes & - & 55 & - \\
Ofídios & - & 2 & - \\
Testudinae & - & 2 & - \\
Aves & - & 47 & - \\
Mamíferos & - & 679 & - \\
TOTAL & - & 65 \\
\hline
\end{tabular}

Grande parte dos vestígios encontrados no sítio é de mamíferos de pequeno e médio porte e de invertebrados do filo Mollusca, todos de ampla ocorrência na Mata Atlântica (Fonseca et al. 1996). Entretanto, os animais de grande porte, como os veados e as capivaras, também foram constantes nas escavações, demonstrando não haver significados diferentes para os guaranis que ocupavam esta região.

Os vestígios são, em sua maioria, provenientes do esqueleto axial e apendicular, e alguns elementos cranianos. Podemos analisar a influência tanto dos processos tafonômicos naturais (e.g. ação de ácidos) (Fig. 7) como aqueles produzidos pela ação antrópica (e.g. preparação de pontas) (Fig. 8) (Binford 1981). Grande parte dos elementos faunísticos apresenta combustão, sendo constante a associação desses com as freqüentes estruturas de fogueiras encontradas por todo o sítio. Podemos ainda diferir entre os elementos calcinados (aspecto branco ou azulado) e os elementos carbonizados (aspecto negro) (Fig. 9). Estas observações indicam que os elementos foram expostos a temperaturas acima de $300^{\circ} \mathrm{C}$, demonstrando que os animais foram preparados diretamente ao fogo e que, possivelmente, após o consumo os elementos serviam de combustível às fogueiras.

Algumas espécies identificadas no Sítio Piracanjuba estão hoje em processo de extinção ou simplesmente não ocorrem mais na área do município de Piraju, devido às modificações ambientais provenientes do manuseio do solo e emprego de novas tecnologias de subsistência.

Os vestígios coletados na superfície nesta etapa de campo são constituídos por fragmentos de ossos de mamíferos (animais de porte grande e médio), em grande parte calcinados, independentemente de sua associação com fogueiras, o que possivelmente demonstre áreas perturbadas por ação de animais ou antrópicas. 


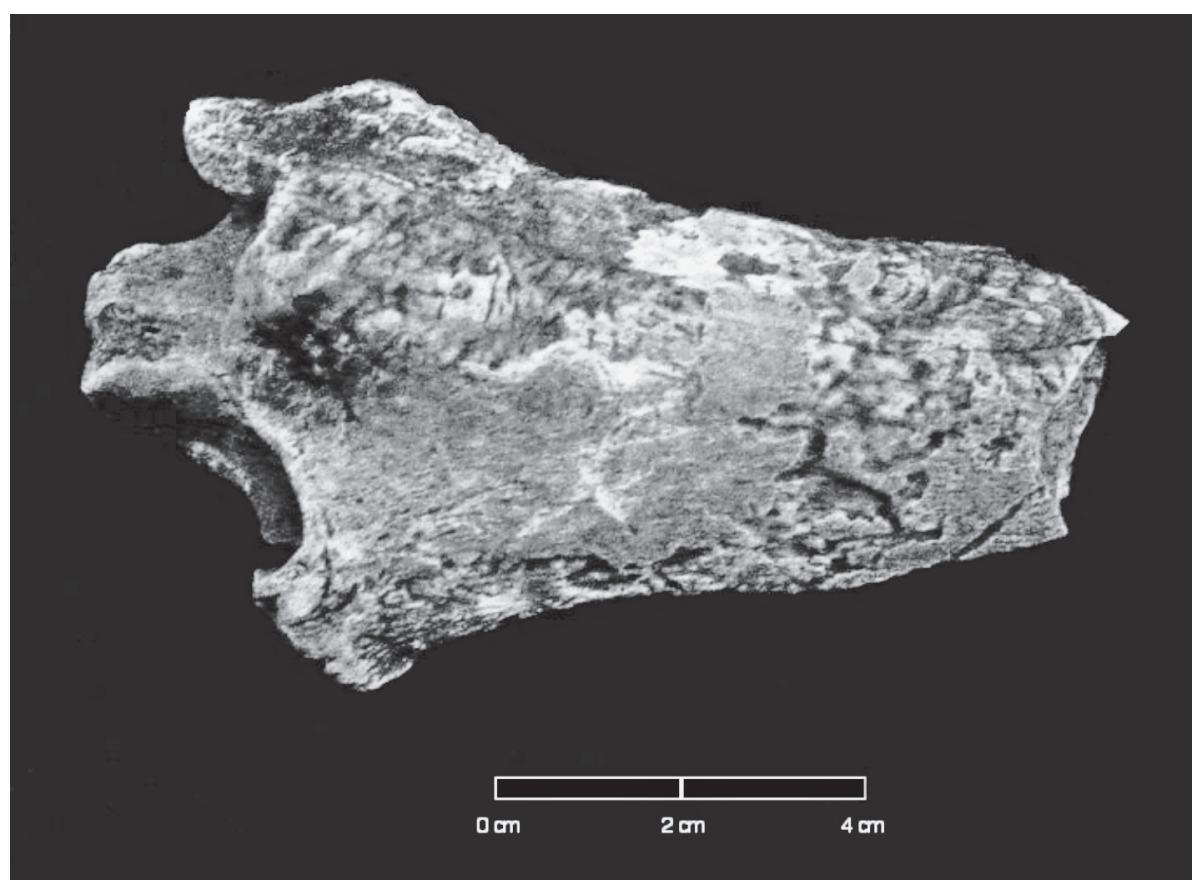

Fig. 7. Corrosão química no processo tafonômico natural.

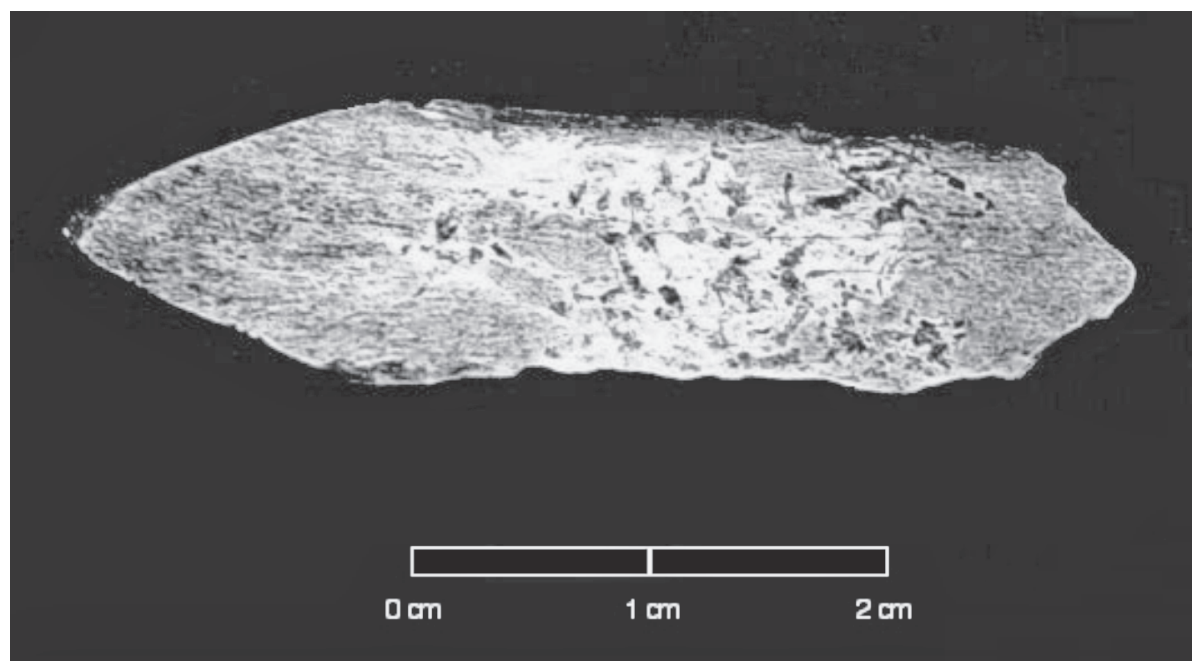

Fig. 8. Artefato feito a partir de osso longo de mamífero. 


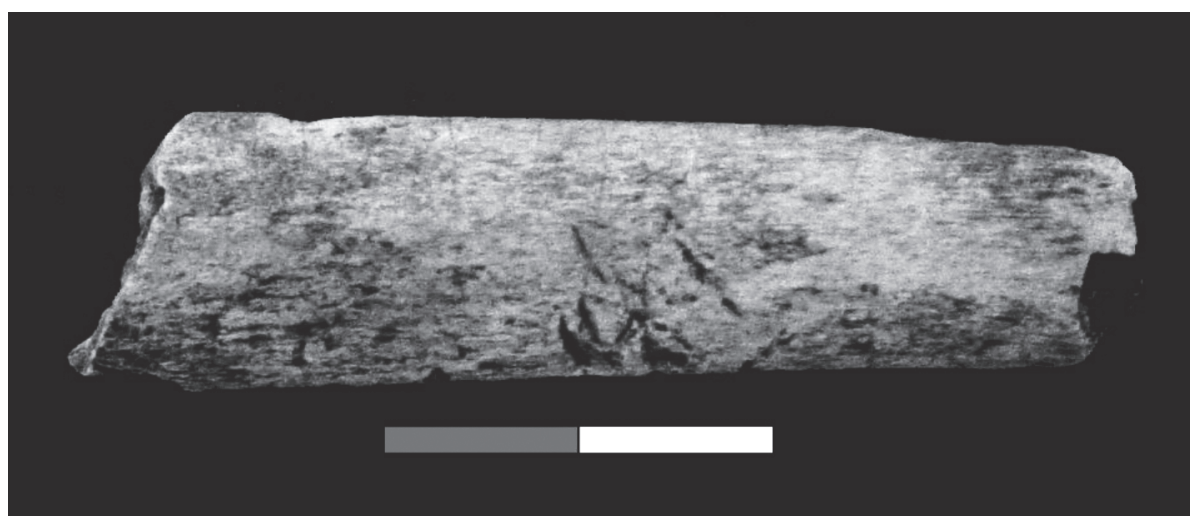

Fig. 9. Osso com marcas de descarne. Escala $=1 \mathrm{~cm}$.

\section{Artefatos}

$\mathrm{Na}$ amostra apresentada ocorreram dois artefatos em ossos de mamíferos, que demonstram o reaproveitamento da matéria-prima para a confecção de instrumentos de trabalho. São duas pontas, uma em forma de bisel, confeccionada a partir da diáfise de osso longo de mamífero de médio porte e outra com a extremidade formando um triângulo eqüilátero (Fig. 8).

\section{Abate e descarne}

Pesquisas sobre modificações em ossos provenientes da ação humana demonstram marcas e modificações superficiais resultantes da utilização de ferramentas para o descarne (Parmalee 1965; Binford 1981).

De acordo com Binford (1981) as marcas encontradas em ossos podem inclusive demonstrar o material da ferramenta utilizada, seja ela em metal ou rocha. As marcas provenientes de ferramentas de metal são alongadas, isoladas e dispersas; as provenientes de rochas são curtas, ocorrem em grupos e de formas paralelas. No caso de entalhes nos ossos, quando provocados por metal possuem as bordas afiladas e contorno retilíneo, e as causadas por rochas possuem bordas rombas e contorno disforme (Binford 1981). Durante os trabalhos de laboratório foram encontrados dois ossos (Fig. 10) com marcas provenientes da ação de descarne, características de terem sido provocadas por instrumento confeccionado em rocha.

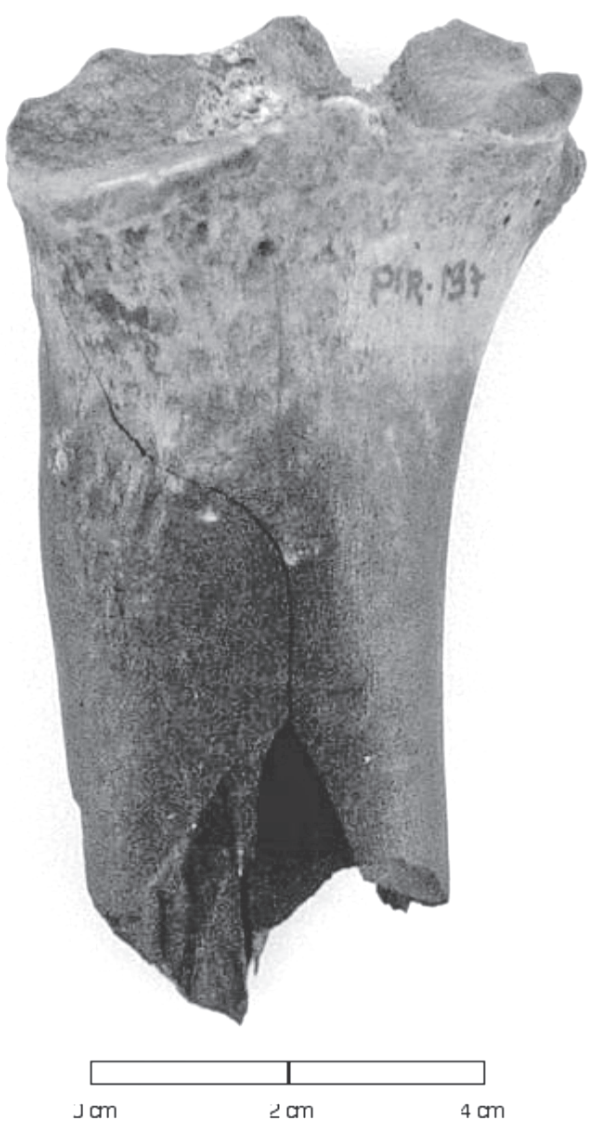

Fig. 10. Osso parcialmente queimado, processo de combustão. 


\section{Conclusão e discussão}

Uma das principais e mais visiveis propriedades dos vestígios faunísticos é a freqüência com que cada elemento ósseo aparece nas escavações (Lyman 2001). Esta freqüência é fundamental para o cálculo de unidades quantitativas que visam à análise específica da fauna encontrada em sítios arqueológicos (Reitz $\&$ Wing 2001). As principais unidades e mais comumente utilizadas na zooarqueologia são o NISP (número de espécimes identificáveis) e o MNI (número mínimo de indivíduos) (Grayson 1984; Lyman 1985; 2001; Reitz \& Wing 2001).

Infelizmente, não pudemos realizar este tipo de análise para todos os NSA's devido à metodologia empregada nas primeiras escavações (não específica para zooarqueologia) e por terem sido escavados apenas alguns trechos do sítio. A análise apresentada neste trabalho demonstra somente o NISP e MNI do "Núcleo de Solo Antropogênico 1".

Grande parte de nossa amostra (78,70 \%), corresponde a elementos ósseos de mamíferos. Quando analisamos estes dados com a disponibilidade de recursos faunísticos da região (74 espécies de peixes e 293 espécies de aves segundo o EIA/RIMA da Usina Hidrelétrica de Piraju (Morais 1996), concluímos que os guaranis possuíam certa seletividade para a captura de alimentos. Poderíamos dizer que as condições geofísicas do sítio poderiam interferir nos processos tafonômicos dos elementos ósseos de peixes e aves, mas, de acordo com Colley (1990), os ossos de peixes estão sujeitos aos mesmos processos tafonômicos do que qualquer outro elemento ósseo no mesmo sítio.

Por outro lado, Schäfer (1972) diz que os elementos faunísticos dos peixes são mais frágeis que os de outros vertebrados, prolongando uma discussão sobre os processos tafonômicos em ossos de peixes que se estende por duas décadas (Colley 1990). Mesmo quando os vestígios de peixes são comuns em muitos contextos arqueológicos, esses tendem a ser raros quando comparados com os vestígios de mamíferos (Lyman 2001). Um dos muitos argumentos sugere que os ossos de peixes são mais vulneráveis aos efeitos de preservação do que os de mamíferos, tornando-os relativamente mais suscetíveis aos processos tafonômicos (Wheeler \& Jones 1989).

Wheeler \& Jones (1989) e Colley (1990) descrevem uma série de fatores tafonômicos de origem antrópica que podem influenciar o registro de peixes no contexto arqueológico, incluindo técnicas de pesca, técnicas de descarne, preparação, práticas de consumo e descarte. Quando aquecidos a uma temperatura de $60^{\circ} \mathrm{C}$ os ossos de peixe perdem parte de seu tecido e das fibras de colágeno (Richter 1986).

A baixa freqüência de elementos faunísticos de peixes no Sítio Piracanjuba está relacionada, provavelmente, com os diversos processos antrópicos (e.g. combustão) e naturais (e.g. acidez do solo) e não com uma coleta seletiva ou qualquer tabu alimentar relacionado com os peixes.

De acordo com o Relatório de Impacto Ambiental da Usina Hidrelétrica de Piraju (Morais 1996), os registros de espécimes de paca, jaguatirica, suçuarana, queixada, cachorro-domato e veado são raros atualmente; espécies que são recorrentes em nossa amostra, o que demonstra o declínio populacional destas devido à sua predação pelo homem nos últimos séculos.

A presença de duas conchas marinhas das espécies Olivancillaria cf. urseus e Neritina virginia indica um possível sistema de trocas entre os grupos do interior e do litoral, já que a distância do Sítio Piracanjuba até o mar é de aproximadamente $450 \mathrm{~km}$. De acordo com Cunha (com. pess.) a identificação da espécie como Olivancillaria urseus deve-se à abundância desta nos registros fósseis e atuais. Este é o segundo registro de conchas marinhas em sítios do interior como descrito anteriormente por Morais \& Piedade (1994) que relatam a ocorrência de um fragmento de exemplar de Tonna galea no Sítio Salto Grande do Paranapanema, também localizado às margens do Rio Paranapanema, sugerindo que esses grupos freqüentavam o litoral ou mantinham contato com populações litorâneas.

Podemos levantar duas hipóteses sobre a freqüência de moluscos no pacote arqueológico: a primeira seria a facilidade de sua coleta quando comparada à caça ou pesca de outros animais, ou a diferença da composição química 
da concha (carbonato de cálcio) com relação ao osso, tornando os bivalves e gastrópodes mais resistentes aos processos tafonômicos naturais.

Pudemos ainda observar a importância da fauna para os guaranis quando analisamos os artefatos e as marcas de descarne nos ossos. O artefato ósseo, um furador, era utilizado na manufatura do couro proveniente da caça que, por sua vez, foi obtida por meio de uma ponta óssea, e as marcas demonstram e comprovam a utilização de material lítico para o processo de descarne (Binford 1981).

\section{Agradecimentos}

Gostaríamos de agradecer a João Carlos Alves e Éverson Paulo Fogolari pelo auxílio na etapa de campo, ao arqueólogo Levy Figuti, pelo auxílio inicial na identificação do material faunístico, ao biólogo Carlo Magenta da Cunha pela identificação das espécies de bivalves e gastrópodes e ao veterinário Ricardo Furquim pelas informações de caracteres diagnósticos de algumas espécies encontradas em nosso trabalho.

GONZALEZ, M.M.B.; PIEDADE, S.C.; MORAIS, J.L. Archaeofauna of Piracanjuba Site, Piraju-SP. Revista do Museu de Arqueologia e Etnologia, São Paulo, 17: 231-249, 2007.

Abstract: The purpose of this essay was to analyze the subsistence of Guarani of Piraju-SP through study of Piracanjuba Site faunal remains. It was evidenced a preference for medium and large animals in the subsistence of the Guarani besides the absence of fish that can be connected to taboos or to the influence of taphonomic processes.

Keywords: Zooarchaeology - Archaeofauna - Guarani.

\section{Referências bibliográficas}

BAKER, J; BROTHWELL, D.

1980 Animal diseases in archaeology. London: Academic Press.

BELOVSKY, G.

1987 Hunter-gatherer foraging: a linear programming approach. Journal of Anthropological Archaeology 6: 29-76.

BINFORD, L.R.

1981 Bones: Ancient men and modern myths. London: Academic Press.

BOWER, J.

1986 In search of the past: An introduction to archaeology. Chicago: The Dorsey Press.

COLLEY, S.M.

1990 The analysis and interpretation of archaeological fish remain. In: Schiffer, M.B. (Ed.) Advances in archaeological method and theory. Tucson, University of Arizona Press, 2: 207-253.
DAVIS, S.J.M.

1987 The archaeology of animals. New Haven: Yale University Press. Fonseca, G.A.B.; Herman, G.; Leite, Y.L.R.; Mittermeier, R.A.; Rylands, A.B.; Patton, J.L.

1996 Lista Anotada dos mamíferos do Brasil. Occasional Papers in Conservation Biology, 4: 1-38.

GRAYSON, D.K.

1984 Quantitative zooarchaeology: topics in the analysis of archaeological faunas. Orlando: Academic Press.

LYMAN, R.L.

1985 Bone frequencies: differential transport, in situ destruction, and the MGUI. Journal of Archaeological Science, 12 (3): 221-236.

2001 Vertebrate Taphonomy. Cambridge Manuals in Archaeology. Cambridge: Cambridge University Press. 
MORAIS, J.L.;PIEDADE, S.C.

1994 O homem pré-histórico de Salto Grande do Paranapanema. Revista do Museu de Arqueologia e Etnologia, 4: 220-222.

MORAIS, J.L.

1996 Relatório de impacto ambiental da Usina Hidrelétrica de Piraju. Volumes IIII, Projeto Paranapanema. São Paulo.

1999 Perpectivas Geoambientais da Arqueologia do Paranapanema Paulista. Tese de livre-docência. Museu de Arqueologia e Etnologia da Universidade de São Paulo.

NOE-NYGAARD, N.

1975 Two shoulder blades with healed lesions from Star Carr. Proceedings of the Prehistoric Society, 41: 10-16.

PARMALEE, P.W.

1965 The food economy of Archaic and Woodland peoples at the Tick Creek
Cave site, Missouri. Missouri Archaeologist, 27 (1): 1-34.

REITZ, E.J.; WING, E.S.

2001 Zooarchaeology. Cambridge: Cambridge University Press.

RICHTER, J.

1986 Experimental study of heat induced morphological changes in fish bone collagen. Journal of Archaeological Science, 13: 477-481.

SCHÄFER, W.

1972 Ecology and paleoecology of marine environments. Chicago: University of Chicago Press.

WHEELER, A.; JONES, A.K.G.

1989 Fishes. Cambridge: Cambridge University Press.

WHITE, T.D.

1992 Prehistoric cannibalism at Mancos 5MTUMR2346. Princeton: Princeton University Press. 


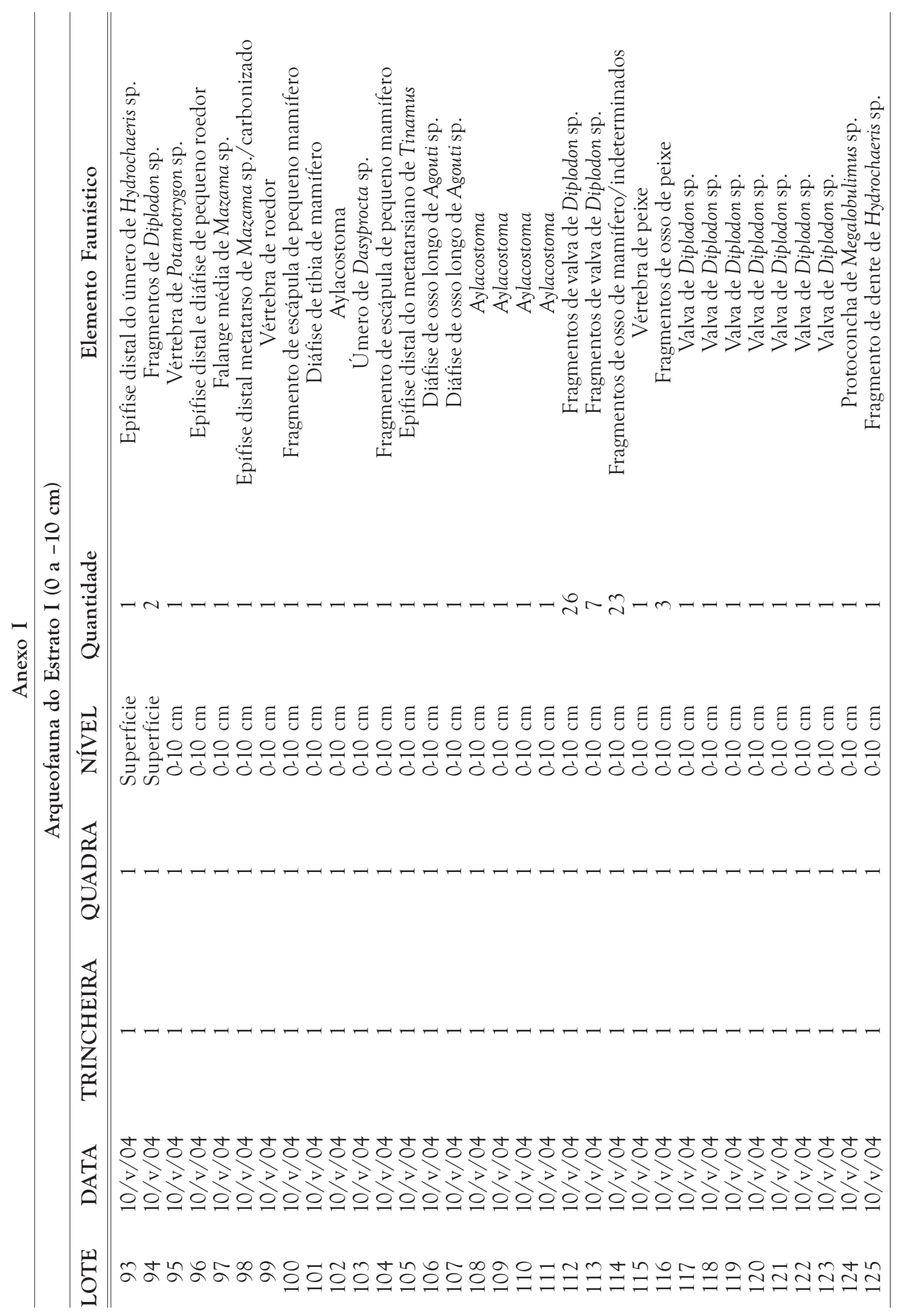




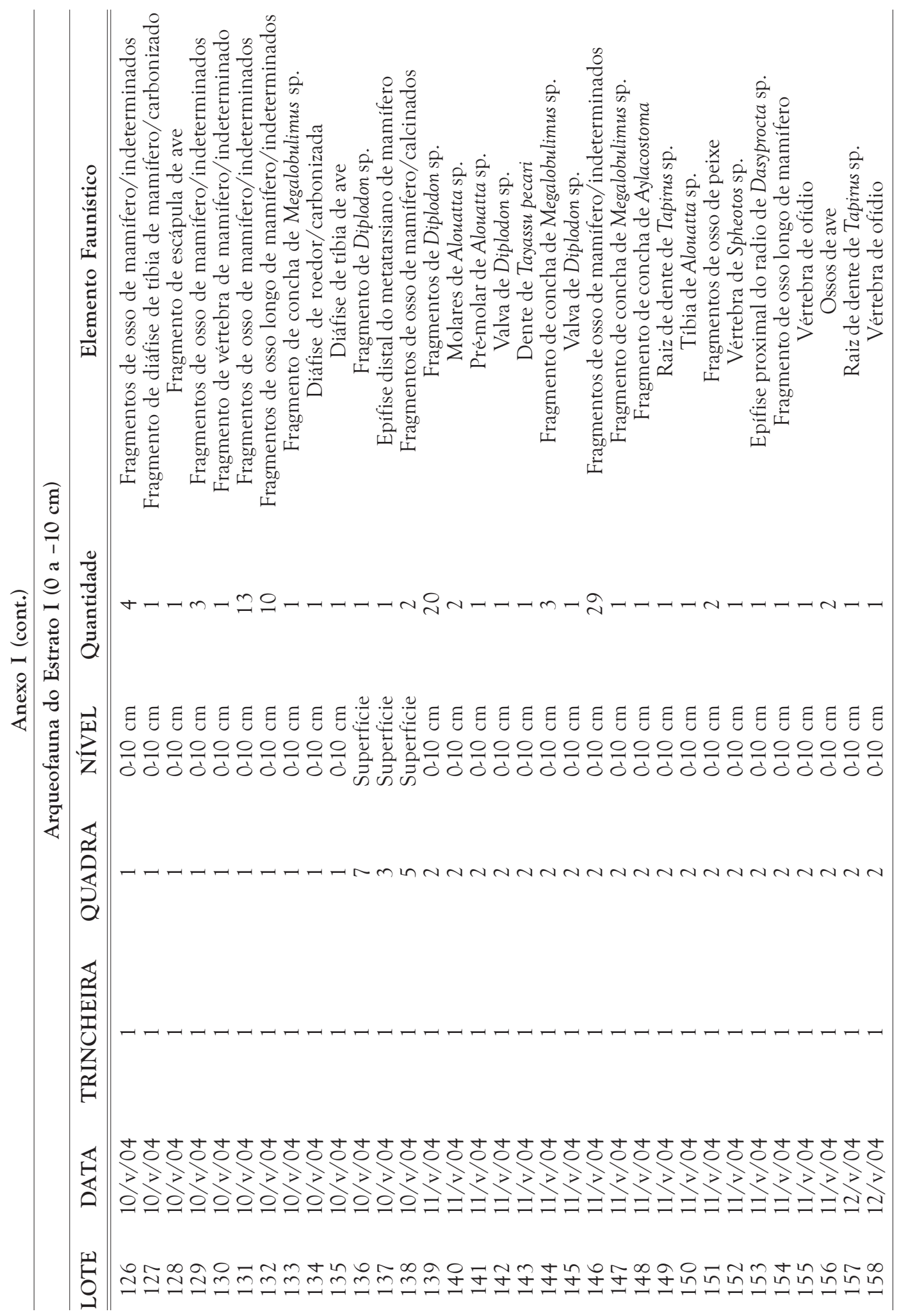




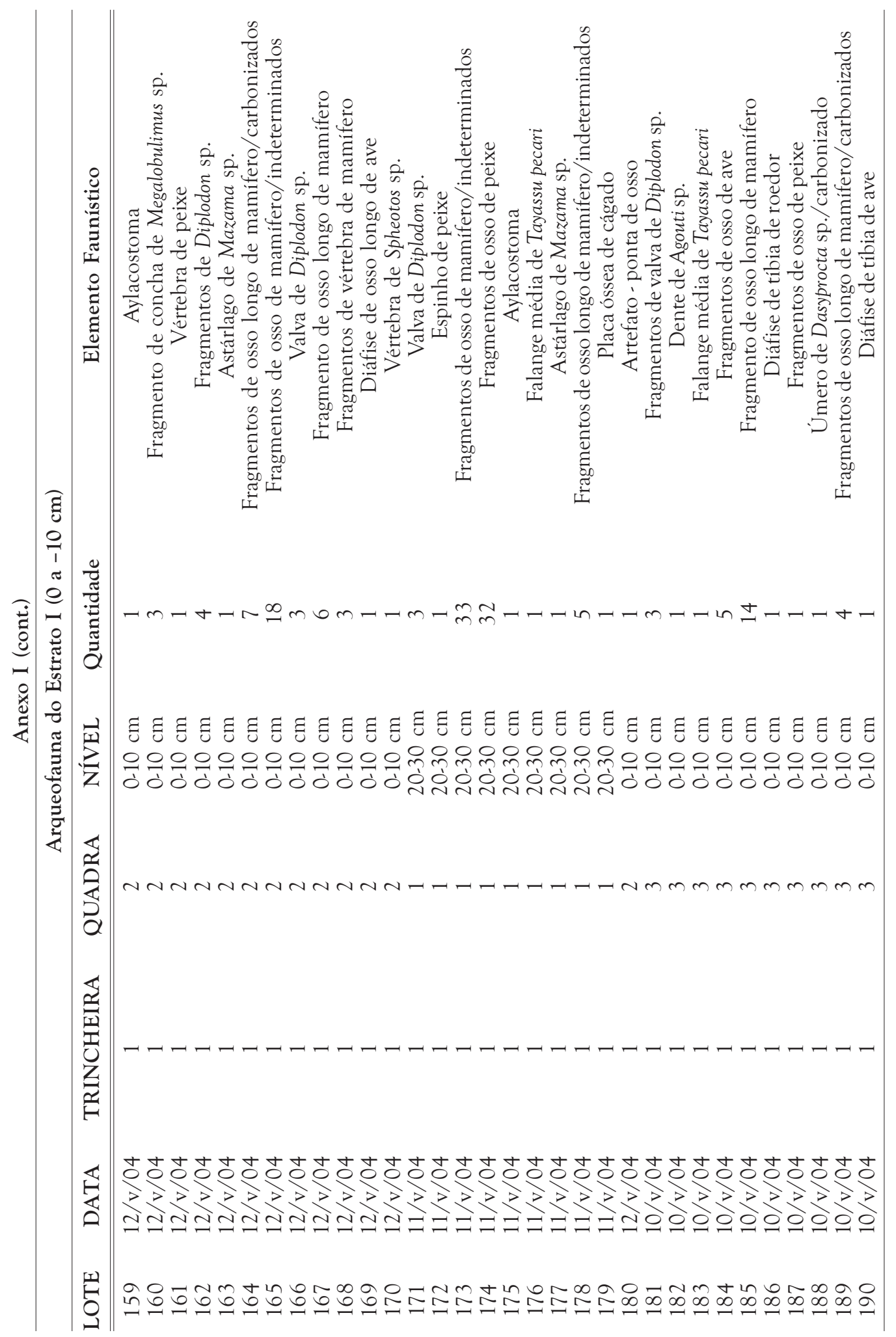




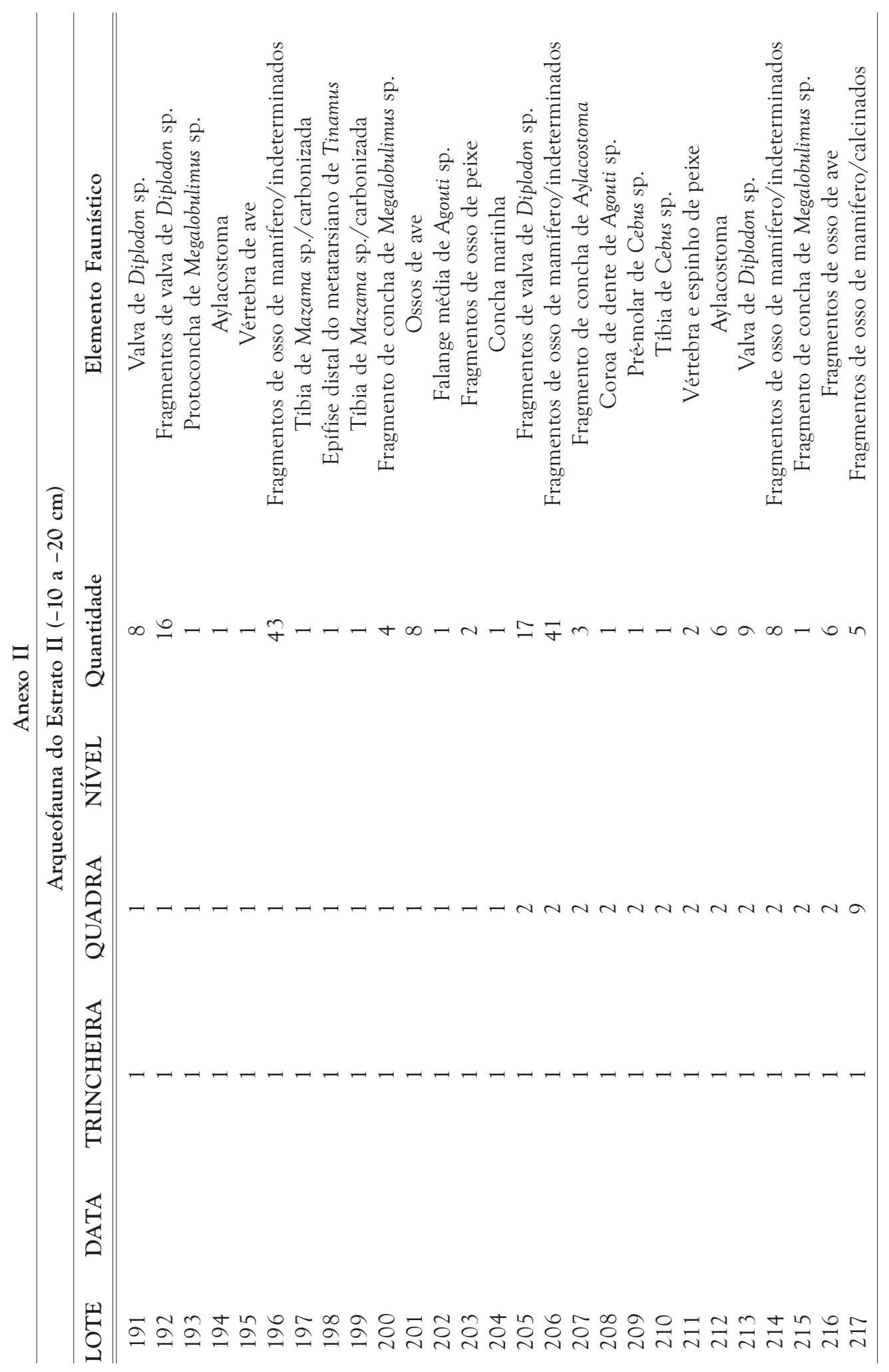




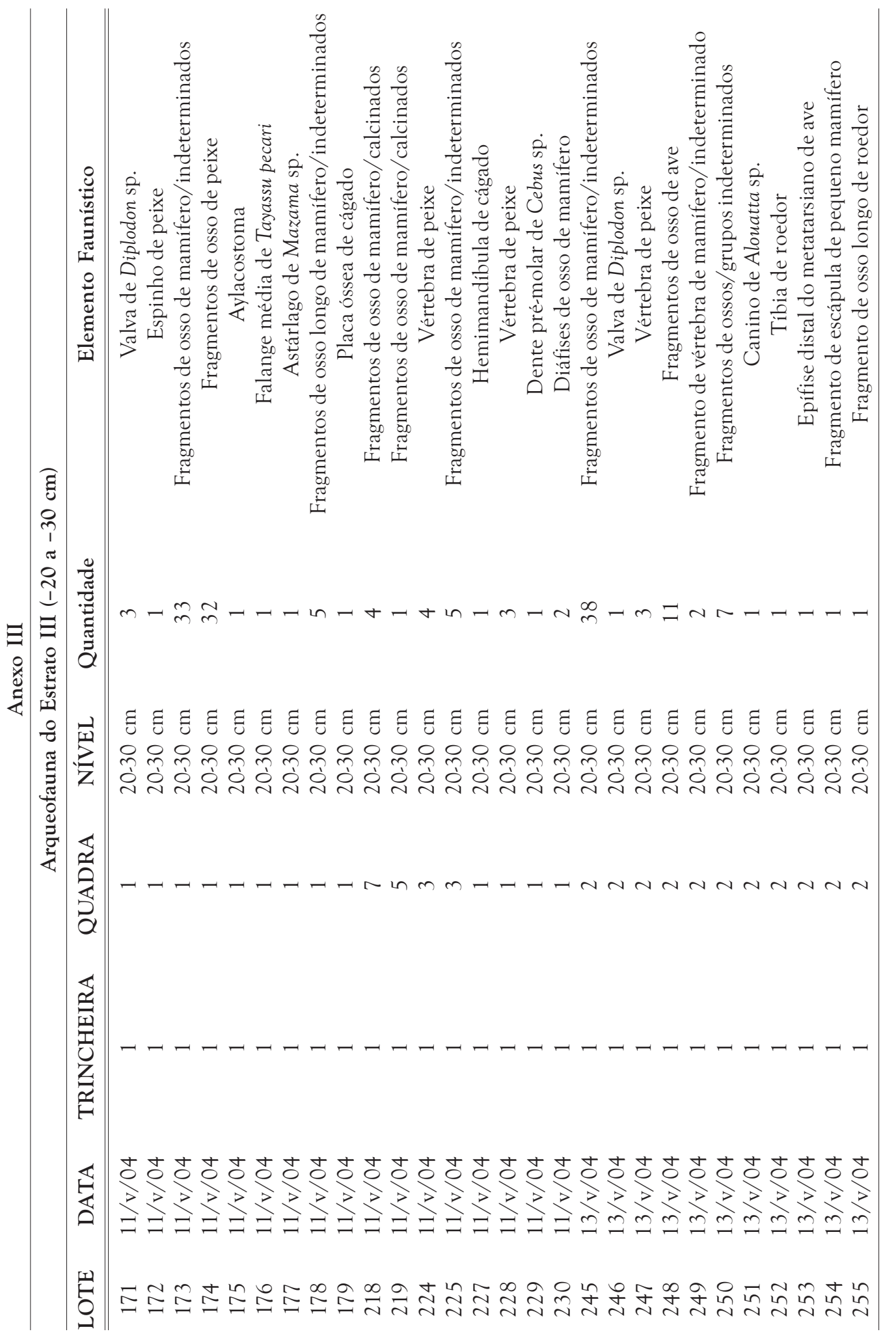




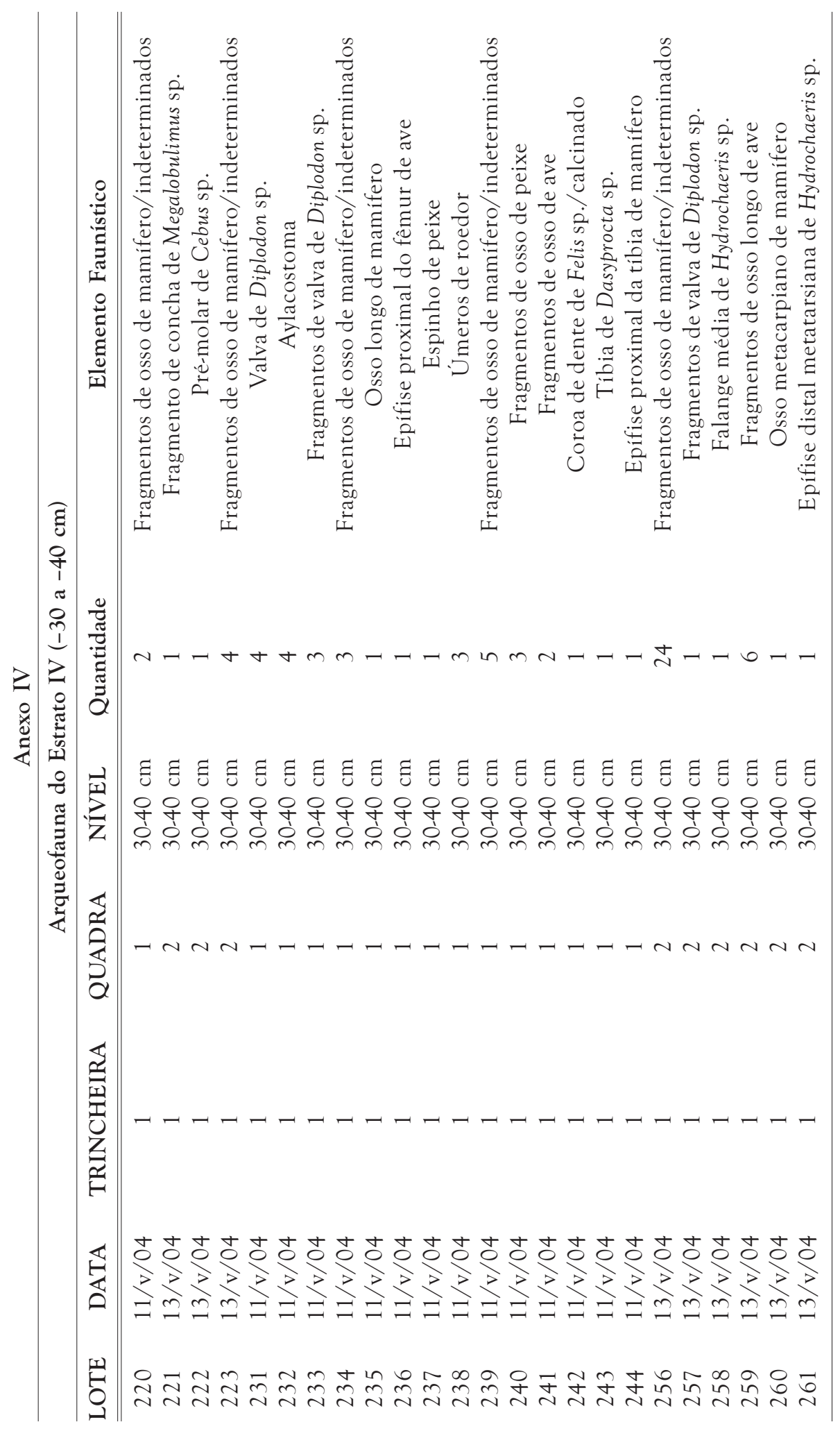

